\title{
Pediatric Peritoneoscopy (Laparoscopy)
}

\author{
David A. Bloom, M.D.* \\ Michael L. Ritchey, M.D.* \\ Gerald H. Jordan, M.D. *
}

\section{Introduction}

$\mathrm{E}$ ver since the dawn of recorded history, medical practitioners have sought the ability to diagnose diseases. At first they used magical methods of divination, but eventually historytaking, physical examination, and diagnostic interventions became common practice in many societies. ${ }^{1}$ For example, the Edwin Smith papyrus, which originated at least 4,500 years in the past, describes injuries and some other ailments in standardized formats of examination, diagnosis, verdict, and treatment. ${ }^{2}$ Two of man's most enduring plagues, bladder stone and urethral stricture, were diagnosed by urethral sounds and sometimes relieved by catheters with a surprising degree of sophistication. Paul of Aegina, in the seventh century, wrote: "When the urine is suppressed in the bladder owing to some obstruction ... we have recourse to catheterism for removal of it. Wherefore, taking a

\footnotetext{
* Department of Surgery, Section of Urology, University of Michigan Medical Center Ann Arbor, Michigan

* Eastern Virginia Medical School, Portsmouth, Virginia, and the Devine Center for Genitourinary Reconstruction Norfolk, Virginia
}

Address correspondence to: David A. Bloom, M.D., Department of Surgery, University of Michigan Medical Center, 1500 East Medical Center Drive, Ann Arbor, MI 48109-0330 catheter proportionate to the age and sex we prepare the instrument for use. ..."3 Throughout the intervening centuries, physicians surely dreamed of the ability to inspect the living body just as they could inspect a cadaver, but only in the past century has this become feasible with the help of general anesthesia (1842), sterile technique (1867), radiology (1895), and antibiotics (1941). Simple inspection even of the accessible portals of the body through optical tubes was impractical until the advent of Edison's electric light (1879) and modern endoscopic instrumentation. In 1865, Francis Cruise, the first to use cystoscopy in Ireland, anticipated the day when any portion of the body would be amenable to direct examination. "I believe it will scarcely be denied that one of the most important characteristics and improvements of modern medicine consists in the direct exploration of organs for the elucidation of their physiology and pathology. . . . The utility of the endoscope is not, however, confined to the diagnosis and treatment of diseases of the urethra - far otherwise - there is no portion of the human body into which a straight tube can be introduced in which it will not be found of service. ..."4

The modern-day "oscopies" (cystourethroscopy, laryngobronchoscopy, esophagogastroscopy, ophthalmoscopy, myringoscopy, and colonoscopy) not only became commonplace with the start of the 20 th century but also helped de- fine and demarcate their respective specialties. Yet Cruise's suggestion implied more than inspection of a body portal; he suggested that any body cavity was amenable to direct visual examination. His prediction lay untested until the turn of the century, when Kelling (1901) and Jacobeus (1910) developed techniques for peritoneoscopy in animals and cadavers and then applied the methods to living patients. ${ }^{5,6}$ Kalk $^{7,8}$ developed instruments for peritoneoscopic examination of the liver, which he first reported in 1929 and eventually performed in over $2,000 \mathrm{pa}-$ tients. ${ }^{8}$ The primary application of peritoneoscopy throughout most of this century has been gynecologic. Diagnostic applications expanded into therapeutic techniques for tubal sterilization and ovarian biopsy. ${ }^{9,10}$ Semm, ${ }^{11,12}$ in Kiel, Germany, carried operative peritoneoscopy much further, developing instruments and techniques that permit a wide range of intracorporeal operative procedures, including adhesionolysis, oophorectomy, appendectomy, and hysterectomy. He has persistently made the point that the term "laparoscopy" is a misnomer because lapara is the Greek term for "flank." Using a strict series of safety steps in more than 20,000 patients, Semm's team proved that diagnostic peritoneoscopy is safe and reliable. Outside gynecologic practice, diagnostic peritoneoscopy grew slowly, in spite of the efforts of its early pioneers. Berci et 


\section{Pediatric Peritoneoscopy (Laparoscopy)}

al and Gans et al ${ }^{13-15}$ were early enthusiasts of the peritoneoscope, but their vision was not contagious. The recent expansion of interest in peritoneoscopic surgery has been facilitated by miniature television cameras and instruments specific to various endosurgical procedures. Intracorporeal suture techniques, as developed by Semm, ${ }^{12}$ were a tremendous advance but require extraordinary skill and are time-consuming. Endoscopic clips and intracorporeal staples, recently available, are much easier to master and shorten the task time.

\section{Peritoneoscopy for Nonpalpable Testis}

In most children with undescended testes, the gonad is palpable; the job of the surgeon is to fix a concomitant inguinal hernia, move the testis gently to a scrotal position, or occasionally remove a small, abnormal gonad. In $10 \%$ to $20 \%$ of undescended testes, however, the gonad is nonpalpable. For these boys, the surgeon's objective is more complex because he must first locate the testis or else prove its absence. Inaccurate declaration of absence may leave behind an occult intra-abdominal testis, with its high risk of eventual malignancy. ${ }^{16}$ The traditional approach for a boy with a nonpalpable testis was inguinal inspection, followed by a more extensive look into the retroperitoneum if a testis was not found; some authors recommended Herculean retraction of the inguinal incision, others extended the incision, and still others made a separate incision. In many cases, a testis was not located and its absence was declared without real proof, that is, without identification of the testicular vessels. Currently, intra-abdominal exploration is mandatory to locate gonadal ves-

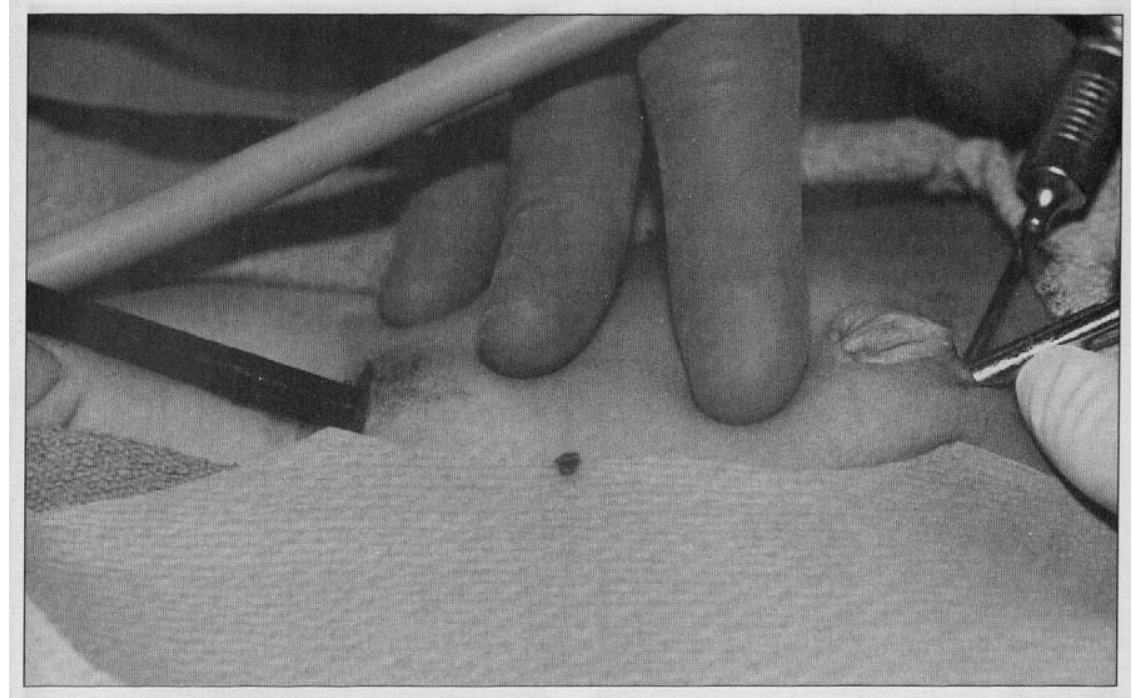

Figure 1. Pediatric peritoneoscopy. A Veress needle (small needle, upper right) is passed through the umbilicus for inflation with $\mathrm{CO}_{2}$. A 5-mm sheath with conical trocar is then passed next to the needle. The trocar is removed and a viewing lens coupled to a television camera is passed through the sheath. When a second port is necessary, as for placement of a spermatic vessel clip, another sheath (black, on left) is passed suprapubically under direct vision.

sels and vas. Although a supracanalicular undescended testis is retroperitoneal in the strict anatomic sense, it and its vessels are best visualized from an intraperitoneal vantage, just as is the case for the ovary. In the absence of an intraabdominal exploration, there is a good chance that a nonpalpable testis may be overlooked. Imaging modalities, such as ultrasonography, arteriography, venography, or CT and MRI scans, have not been reliable in either finding the testis or proving its absence. Following the lead of Cortesi et al, Silber and Cohen, Scott, and Lowe et al, we have found pelviscopy an ideal first operative step in managing patients with nonpalpable testes ${ }^{17-22}$ (Figure 1).

Pelviscopy is accurate in either finding a nonpalpable testis or proving its absence in more than $96 \%$ of patients. Our endoscopic findings usually consisted of blindending spermatic vessels with an absence of the gonad, an intra-abdominal testis, inguinal hernia, or testes below the internal ring that had been missed on preliminary examinations (these testes were often bilateral and hypoplastic) (Figure 2). In addition, this approach permits endoscopic management of abdominal testes with two-step vasal pedicle orchiopexy. A clip is applied endoscopically to occlude the testicular vessels and stimulate formation of collaterals. After a six-month interval, open surgical orchiopexy is performed, dividing the spermatic vessels with the confidence that the entire blood supply is maintained by the vasal collaterals $^{23}$ (Figure 3). Complete endoscopic Fowler-Stephens orchiopexy may soon be commonplace. ${ }^{24}$ Endoscopic orchiectomy for a nonsalvageable testis is a simple part of the laparoscopic surgical armamentarium.

\section{Other Applications of Operative Peritoneoscopy}

Waldschmidt and Schier, ${ }^{25}$ in Berlin, began to use laparoscopy in neonates and children in 1978 


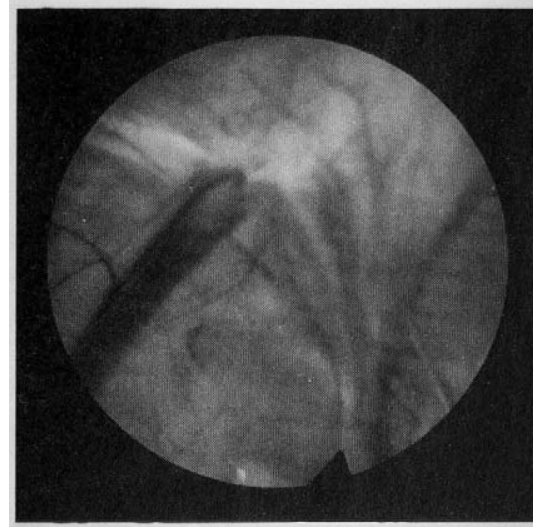

a)

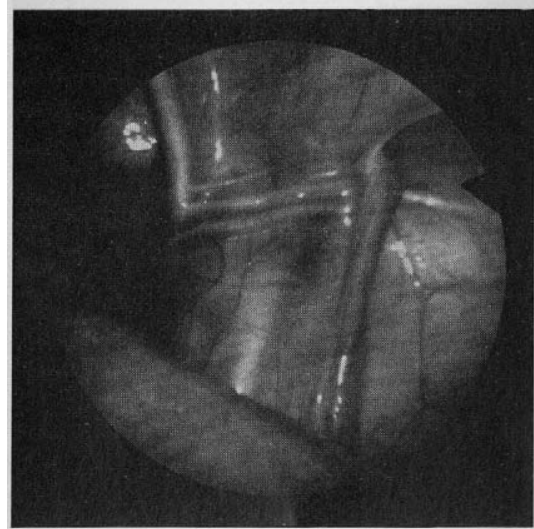

c)

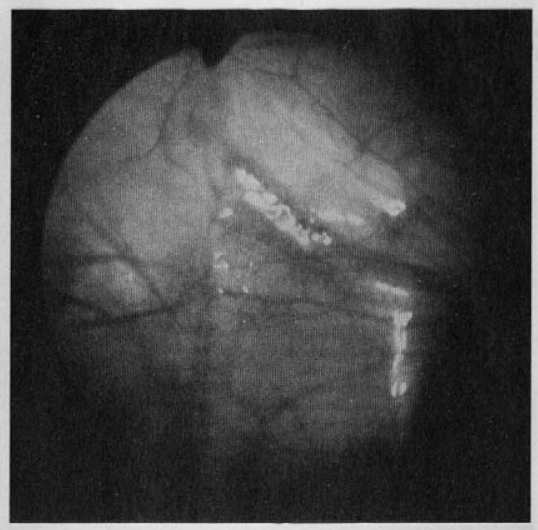

b)

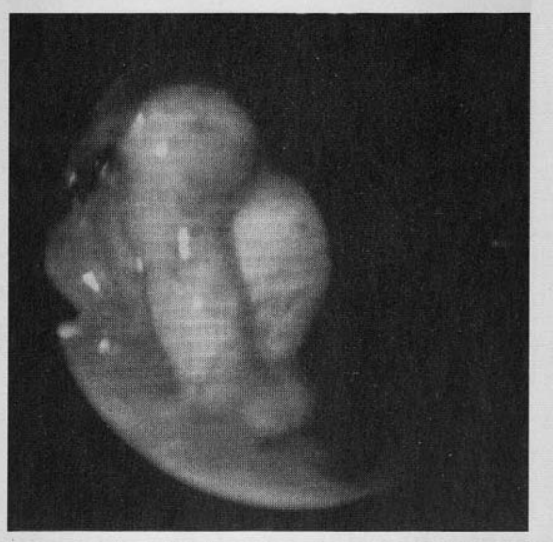

d)

Figure 2. Typical pelviscopic findings in boys with nonpalpable testes: a) Normal anatomy (vas and spermatic vessels) at internal inguinal ring, suggesting that now or in the past a testis passed by this point. On inguinal exploration there either will be a testis or the vessels will end blindly distal to the internal inguinal ring. b) Blind-ending spermatic vessels proximal to the internal ring, with no distal gonad. c) Hernia sac containing a distal testis. d) Abdominal testis.

and reported 136 procedures, not only for undescended testis but also for intersex evaluation, adhesionolysis, and gonadectomy. Semm ${ }^{12}$ became quite facile at endoscopic appendectomy, and others have taken up this approach.$^{26} \mathrm{En}$ doscopic varicocelectomy is commonplace in adult practice and may have application in children. In the expert hands of Winfield et $\mathrm{al}_{,}{ }^{27}$ the endoscopic procedure is safe and reliable. Endoscopic magnification permits isolation and salvage of the artery and lymphatics. Furthermore, venous collaterals which could lead to recurrence of the varicocele are detected with far greater ease than at the time of open varicocelec- tomy, with its much narrower field of vision.

Abdominal complications of ventriculoperitoneal shunts, such as entrapment, displacement, or cyst formation, can be diagnosed and corrected endoscopically, using one or two additional ports. ${ }^{28,29}$ Endoscopic herniorrhaphy was pioneered in adults by $\mathrm{Ger},{ }^{30}$ who used a stapler to occlude the neck of the indirect hernia sac and place a synthetic mesh to occlude a direct hernia. The procedure takes about half an hour and can also be applied to recurrent or femoral hernias. For children, however, inguinal hernia repair is already an outpatient procedure with very minimal morbidity. Furthermore, the incisional length in millimeters for an endoscopic approach surely rivals or exceeds the length of a standard pediatric hernia incision. The trocars, forceps, and endoscissors are potentially lethal instruments for any patient, especially for an infant or child, and it remains to be proved that safety and economy are not sacrificed for novelty, insofar as routine pediatric herniorrhaphy is concerned.

Laparoscopy has revolutionized cholecystectomy in the past few years, and the favorable adult experience has been duplicated in children. ${ }^{31-33}$ As recently as 1991, a diagnostic and therapeutic technology assessment indicated that this was a promising technique, but only $12.5 \%$ of consultants believed it safe. ${ }^{34}$ Since then, public demand and professional interest in this procedure have intensified, and laparoscopic cholecystectomy has become the standard of practice for adults in more and more centers and communities. ${ }^{35}$ Pyloromyotomy, as demonstrated in children by Alain et $\mathrm{al}^{,{ }^{36}}$ is an attractive possibility. Sahlev et $\mathrm{al}^{37}$ performed endoscopic detorsion of adnexa in girls.

Only a few years ago the idea of laparoscopic nephrectomy would have been assigned to the category of science fiction. Clayman and associates, ${ }^{38}$ in a paradigm of ingenious and persistent clinical investigation, perfected the technique in pigs and have successfully extended it to humans. This procedure is an order of magnitude more difficult than cholecystectomy, given that the kidney is retroperitoneal, has a very significant blood supply, and usually requires morcellation for removal. Operative time averages more than five hours but drops with experience, and some cases have been completed in as few as two hours. Partial nephrectomy is also possible by this route, but the tech- 


\section{Pediatric Peritoneoscopy (Laparoscopy)}

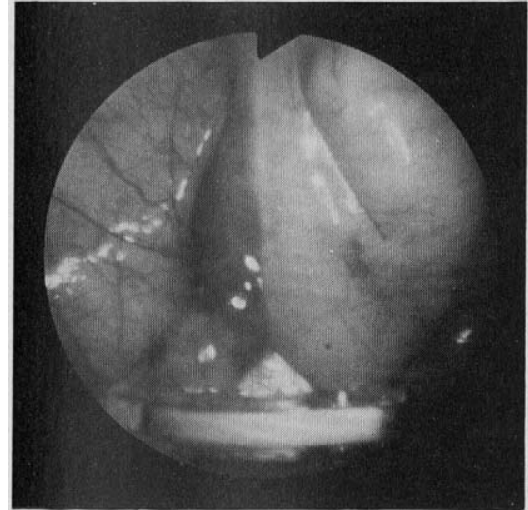

a)

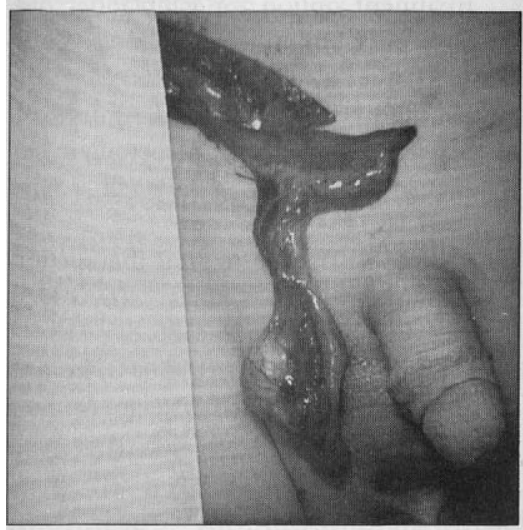

n)

Figure 3. a) Spermatic vessels after clip application. b) Six months later, after blood supply has been reconstituted through vasal collaterals, the abdominal testis is explored surgically. This one has a long hairpin turn of the vas deferens. c) Once the hairpin turn has been straightened, there is enough length for the testis to be placed in the scrotum. d) Follow-up at one year.

niques and logistics are still under evaluation. Complete pelvic lymph node dissection in patients with bladder or prostatic carcinoma is a straightforward procedure with minimal morbidity in the hands of trained laparoscopic surgeons. In children, however, the reasons for pelvic or retroperitoneal node sampling are unusual. Lymphocele management is similarly possible, although this also is an unusual condition in childhood. ${ }^{39}$ Schuessler (personal communication, 1992) has performed pelviscopic bladder neck suspension (Marshall-Marchetti-Kranz), and his team has been developing techniques for endoscopic radical prostatectomy. Kozminski and

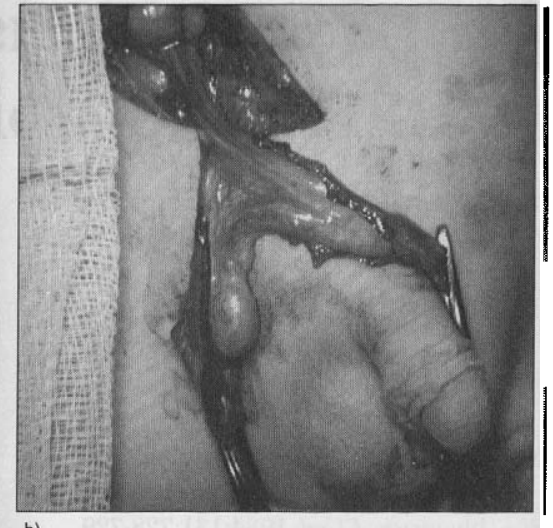

b)

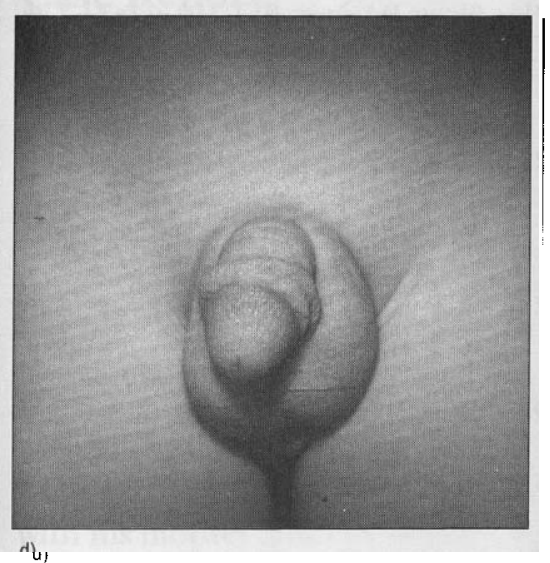

4)

associates (personal communication, 1992) have performed ileal conduit urinary diversions using peritoneoscopic technique for most of the procedure. This is clearly an operation of extraordinary complexity, and whether it is better than open surgery will await the test of time and experience.

\section{Complications of Peritoneoscopy}

The most frequent complications are minor and tend to be involved with the passage of the Veress needle or trocars; these include abdominal wall bleeding, preperitoneal/retroperitoneal in- sufflation, or minor lacerations of the omentum, mesentery, or bowel surface. More serious complications include visceral or vascular punctures that require open surgical intervention for control. Unattended intracorporeal instruments can also cause visceral or vascular injury. At any moment during peritoneoscopic surgery, complications may demand open laparotomy. Excessive intraperitoneal pressures (over $20 \mathrm{~mm} \mathrm{Hg}$ ) can impede venous return. Delayed complications include infection, omental evisceration, and adhesion formation. ${ }^{41}$

\section{Conclusion}

With the applications of operative peritoneoscopy developing so rapidly, it is likely that newer techniques will be added to the armamentarium faster than publications are generated. On the one hand, endoscopic approaches will offer practical alternatives with decreased morbidity, compared with conventional surgery. On the other hand, just because something is new does not mean it is better; for some patients and disorders, conventional open operative procedures will remain the wiser choice. Endoscopic techniques, like other operative procedures, are not free of risk, and complications will accrue. These will need to be reported and analyzed. Laparoscopic surgery is here to stay, although time and experience will shape its role.

\section{REFERENCES}

1. Osler W. The Evolution of Modern Medicine. New Haven, CT: Yale University Press; 1921.

2. Breasted JH. The Edwin Smith Surgical Papyrus. Chicago, IL: University of Chicago Press; 1930. 
3. Adams F. The Seven Books of Paulus Aegineta. Vol. 2, book 6, sec 59. London, England: Sydenham Society; 1846:351.

4. Cruise FR. The utility of the endoscope as an aid in the diagnosis and treatment of disease. Dublin $Q J$ Med Sci. 1865;39:329-363.

5. Kjelling G. Zur celioscopie. Arch $\mathrm{Klm}$ Chir. 1923;126:226.

6. Jacobeus HC. Ueber die moglichkeit die zystoscopie bei untersuchung seroser hohlungen anzuwenden. Munch Med Wochenschr. 1910;57:2090-2092.

7. Kalk H. Erfahrungen mit der laparoscopie. Z Klm Med. 1929;111:303.

8. Kalk H, Bruhl W. Leittachen der Laparscopie. Stuttgart, Germany: Thieme Publishers; 1951.

9. Power SH, Barnes AC. Sterilization by means of peritoneoscopic tubal fulguration. A preliminary report. Am J Obstet Gynecol. 1941;41:1038-1043.

10. Palmer R. La celioscopie gynecologique. Rapport du Professeur Mocquet. Acad de Chir. 1946;72:363-368.

11. Semm K; Friedrich ER, trans. Operative Manual for Endoscopic Abdominal Surgery. Chicago, IL: Yearbook Medical Publishers Inc; 1987.

12. Semm K. Endoscopic appendectomy. Endoscopy. 1983;15:59-64.

13. Berci G, Shore JM, Parrish J, et al. The evaluation of a new peritoneoscope as a diagnostic aid to the surgeon. Ann Surg. 1973;178:37-39.

14. Gans SL, Berci G. Advances in endoscopy of infants and children. $J$ Pediatr Surg: 1971;6:199-234.

15. Gans SL, Berci G. Peritoneoscopy in infants and children. I Pediatr Surg. 1971;8:399-405.

16. Brothers LR III, Weber CH Jr, Ball TP Jr. Anorchism versus cryptorchidism: the importance of a diligent search for intra-abdominal testes. $J$ Urol.
1978;1 19:707-708.

17. Cortesi N, Ferrari P, Zambarda E, et al. Diagnosis of bilateral abdominal cryptorchidism by laparoscopy. Endoscopy. 1976;8:33-34.

18. Silber SJ, Cohen R. Laparoscopy for cryptorchidism. J Urol. 1982;128:829830.

19. Scott JES. Laparoscopy as an aid in the diagnosis and management of the impalpable testis. J Pediatr Surg. 1982;7:1416.

20. Lowe DH, Brock WA, Kaplan GW. Laparoscopy for localization of nonpalpable testes. J Urol. 1984;131:728-729.

21. Bloom DA, Ayers JWT, McGuire EJ. The role of laparoscopy in management of nonpalpable testes. J Urol. 1988;94:465470 .

22. Bloom DA, Semm K. Advances in genitourinary laparoscopy. In: LyttonB, ed. Advances in Urology. Vol. 4. Chicago, IL: Mosby-Yearbook; 1991:167-182.

23. Bloom DA. Two-step orchiopexy with pelviscopic clip ligation of the spermatic vessels. J Urol. 1991;145:1030-1033.

24. Jordan GJ. Laparoendoscopic surgical management of the abdominal/transinguinal undescended testis. $J$ Endourol. In press.

25. Waldschmidt J, Schier F. Laparoscopical surgery in neonates and infants. Eur JPediatr Surg. 1991;1:145-150.

26. Gotz F, Pier A, Bacher C. Modified laparoscopic appendectomy in surgery. Surg Fndosc. 1990;4:6-9.

27. Winfield HN, Donovan JF, See WA, et al. Urological laparoscopy surgery. $J$ Urol. 1991;146:941-948.

28. Rodgers BM, Talbert JL. Laparoscopy in the diagnosis and treatment of malfunctioning ventriculoperitoneal shunts in children. J Pediatr Surg. 1978;13:247-253.

29. Morgan WW Jr. The use of peritoneos- copy in the diagnosis and treatment of complications of ventriculoperitoneal shunts in children. I Pediatr Surg. 1979;14:180-181.

30. Ger R, Monroe K, Duvivier R, Mishrick A. Management of indirect inguinal hernias by laparoscopic closure of the neck of the sac. Am J Surg. 1990;159:370373.

31. Holcomb GW III, Olsen DO, Sharp KW. Laparoscopic cholecystectomy in the pediatric patient. $J$ Pediatr Surg. 1991;26:1186-1190.

32. Sigman HH, Laberge J-M, Croitoru D, et al. Laparoscopic cholecystectomy: a treatment option for gallbladder disease in children. $J$ Pediatr Surg. 1991;26:1181-1183.

33. Newman KD, Marmon LM, Attori R, et al. Laparoscopic cholecystectomy in pediatric patients. $J$ Pediatr Surg. 1991;26:1184-1185.

34. Cole HM. Diagnostic and therapeutic technology assessment (DATTA). JAMA. 1991;265:1585-1586.

35. Dubois F, Icard P, Berthelot G, Levard H. Celioscopic cholecystectomy: preliminary report of 36 cases. Ann Surg. 1990;211:60.

36. Alain JL, Grousseau D, Terrier G. Extramucosal pylorotomy by laparoscopy. $J$ Pediatr Surg. 1991;26:1191-1192.

37. Shalev E, Mann S, Romano S, et al. Laparoscopic detorsion of adnexa in childhood: a case report. J Pediatr Surg. 1991;26:1193-1194.

38. Clayman R. In press.

39. Waples MJ, Wegenke JD, Vega RJ. Laparoscopic management of lymphocele after pelvic lymphadenectomy and radical retropubic prostatectomy. Urology. 1992;39:82-84.

40. Bloom DA, Ehrlich RM. Omental evisceration through small laparoscopic ports. JEndourol. In press. 